\title{
THREE SUBGROUPS OF PATIENTS FROM THE UNITED KINGDOM WITH LEBER HEREDITARY OPTIC NEUROPATHY
}

\author{
DAVID A. MACKEY \\ Melbourne, Australia
}

\begin{abstract}
SUMMARY
Variations in classic Leber hereditary optic neuropathy (LHON) include recovery of vision and association with other neurological abnormalities. Sixteen multi-generational Australian families originating from the United Kingdom with LHON were studied by the one examiner, using the same protocol. In particular, recovery of vision and other neurological abnormalities were noted. One very large family (Tas2) and one small family (Vic2) were found to have frequent recovery of vision $\mathbf{5 0 \%}$ of patients). They both had the $14484 \mathrm{~T}$ to $\mathrm{C}$ mutation in their mitochondrial DNA (mtDNA). One apparently unique family (QId1) was found to have frequent juvenile encephalopathy and peripheral neurological signs. They had the $4160 \mathrm{~T}$ to $\mathrm{C}$ and $14484 \mathrm{~T}$ to $\mathrm{C}$ mutations. The remaining 13 families rarely showed visual recovery or associated neurological abnormalities. They had the common $11778 \mathrm{G}$ to $\mathrm{A}$ or the $3460 \mathrm{G}$ to A mutations. Thus mitochondrial genotypes in LHON are associated with variable phenotypes.
\end{abstract}

Leber hereditary optic neuropathy (LHON) is one of the most devastating forms of hereditary blindness, mainly affecting young men in their twenties with bilateral simultaneous or sequential loss of vision. ' LHON also affects some women and may occur at any age. Loss of vision is usually the only abnormality, with occasional reports of neurological abnormalities ${ }^{2-10}$ and rare cases of visual recovery. ${ }^{11-13}$ Colour vision is abnormal and there is a large centrocecal scotoma. Acutely the optic nerve may appear normal or may be slightly elevated with associated peripapillary telangiectasia. ${ }^{14}$ Later, however, the disc becomes atrophic.

Australia has a population nearing 17 million of whom $85 \%$ originate from the British Isles. Extensive clinical and genealogical research has identified virtually every

Correspondence to: Dr David A. Mackey, University of Melbourne Department of Ophthalmology, 32 Gisborne Street, East Melbourne. Victoria 3002, Australia. case of LHON in Australia and traced almost all maternal line relatives, affected or unaffected. ${ }^{15}$ Records show that all 16 large Australian pedigrees originated from the United Kingdom or Ireland, and we have located the regions where each family originated (Fig. 1). In most cases we have traced the families back further in the United Kingdom. Three sporadic cases with no family history of LHON were also identified. ${ }^{15}$

Mitochondrial DNA (mtDNA) analysis has identified several point mutations in the mtDNA and these are given for each of the large Australian families with multiple affected individuals. ${ }^{16}$ From clinical studies of the different families it was evident that there were some phenotypic differences between them ${ }^{6.17}$ and that these correlated with the genotype. ${ }^{18.19}$ Work in the United States has also shown that the various genotypes have variable phenotypes. ${ }^{20} 2.3$

\section{METHOD}

Patients and pedigrees were identified using the strategies outlined in the Methods section of the previous study. ${ }^{15}$ With informed consent DNA was taken and studied for the various mtDNA mutations. ${ }^{2+}$ The primers for screening the 14484 mutation are outlined in the Method section of Johns et al. ${ }^{23}$ Confirmation of the mutations was performed by N. Howell's laboratory in Galveston, Texas, by direct sequencing.

Patients were questioned about their visual loss, and old records obtained where possible. Patients were examined according to the 'visual function tests' protocol of the optic neuritis treatment trial. ${ }^{25}$ This included: Snellen acuity, Logmar acuity, Pelli-Robson contrast sensitivity, Goldmann fields, Humphrey 30-2 visual fields, Ishihara plates, Farnsworth-Munsell 100 Hue test, fundus examination, and general neurological examination. It became evident early in the study that much of this examination was either not duplicated easily, or not reliable, and that the results could not be meaningfully compared. The

Eye (1994) 8, 431-436 C 1994 Royal College of Ophthalmologists 


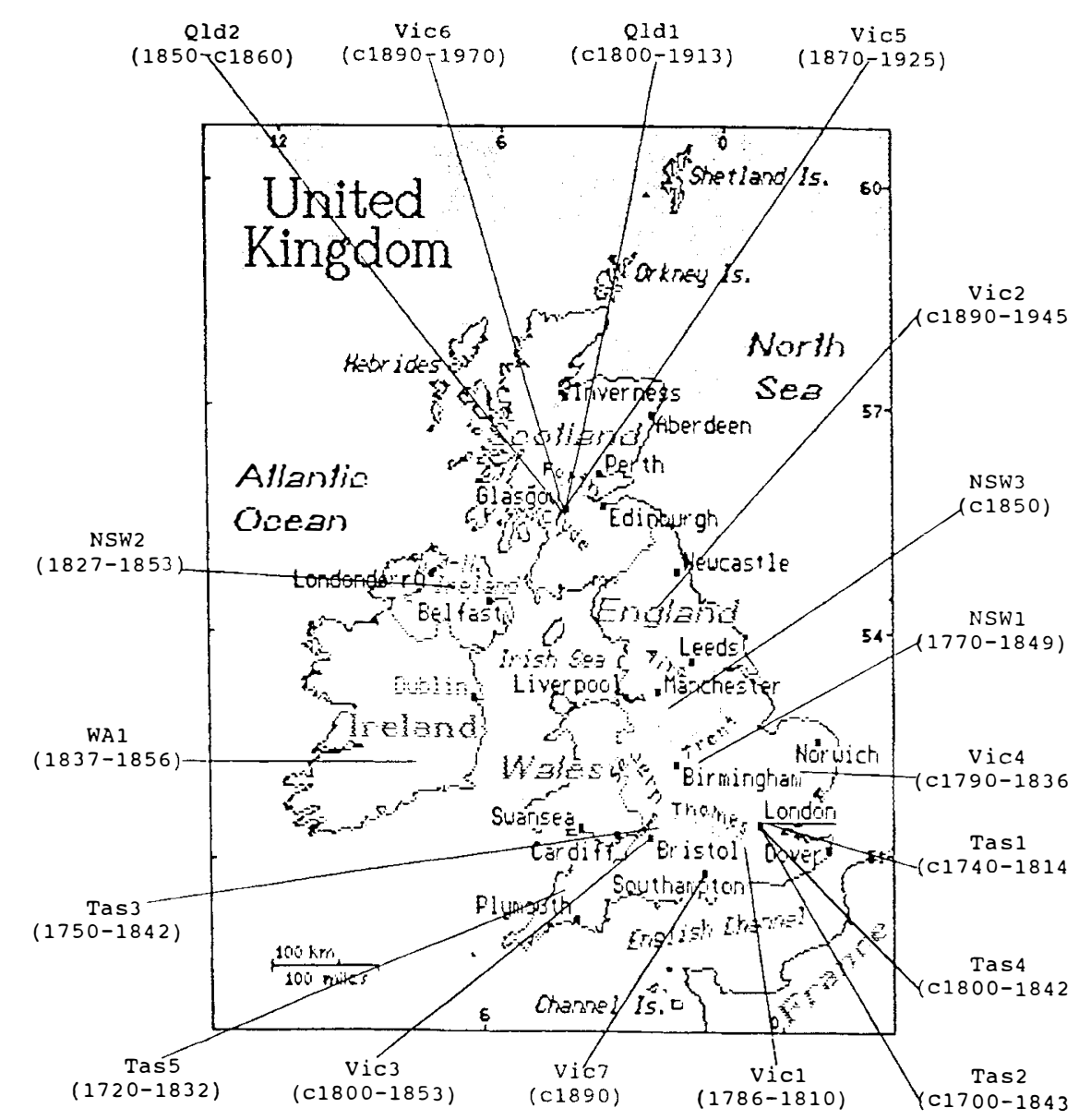

Fig. 1. Origins of the Australian Leher hereditary optic neuropathy (LHON) families. The first date is the earliest record of the family in the United Kingdom; the second is the date of emigration to Australia.

results of the study were therefore confined to examination of Snellen acuities, Farnsworth-Munsell 100 Hue test, fundal and neurological examination and the Humphrey 30-2 fields. (The Humphrey 30-2 field test was reliably standardised throughout Australia and allowed the examiner to monitor visual fixation continually and pause the test if required. With the Goldmann field it is not possible to observe the patient continuously and do the test. The Humphrey computer re-checks readings that are inconsistent and the results are thus much more reliable. The Humphrey 30-2 field test is discussed as being most reliable in the optic neuritis treatment trial. $)^{25}$

\section{RESULTS}

For the total number of patients in the Australian pedigrees with LHON readers are referred to the earlier paper. ${ }^{15}$ From these, 199 blind descendants of 13 families had the $11778 \mathrm{G}$ to A mutation; 7 blind descendants of 2 families had the $3460 \mathrm{G}$ to A mutation; 41 blind descendants from 1 family had the $4160 \mathrm{~T}$ to $\mathrm{C}$ mutation and the $14484 \mathrm{~T}$ to $\mathrm{C}$ mutation; 66 blind descendants from 2 families had the $14484 \mathrm{~T}$ to $\mathrm{C}$ mutation and the $13708 \mathrm{G}$ to $\mathrm{A}$ mutation. Only 1 Italian female had the isolated $15257 \mathrm{G}$ to A mutation, while 7 members of a $11778 \mathrm{G}$ to A family (already counted above) also had this mutation. There are 19 families here because the 3 singleton cases have been included with these mutations.

\section{Mutation 11778}

Mutation 11778 occurs in many families originating throughout the British Isles and is the most common mutation. Of over 50 (from 92 living) patients with the 11778 mutation who were questioned directly or by telephone only 1 reported recovery of vision. Their acuities were all reported as less than $6 / 60$, except 1 male who recovered to VR 6/36 VL 6/6. One female had associated multiple sclerosis affecting her lower limbs and bladder and severe visual loss consistent with LHON. Visual fields were examined in 10 males, including the male with recovery of vision from less than $6 / 60$ in both eyes to VR 6/36 VL $6 / 6$, and all showed dense central scotomata. This patient who recovered had such a small island of vision within his centrocecal scotoma that it could not be detected on any type of field examination (Fig. 2). Most could hardly do the Farnsworth-Munsell 100 Hue test and tended to have errors in the deutan axis. The classic triad of optic disc elevation, peripapillary telangiectasia and no leakage on fluorescein angiography ${ }^{26}$ had been photographed or seen in 12 patients, but probably was not reported in many cases because of the subtlety of these signs. The family with both the 11778 and 15257 mutations was not examined by the protocol described in the Method section, but all 7 individuals were reported to have dense centrocecal scotomata and poor vision.

The mean age of loss of vision in the 11778 group (with 


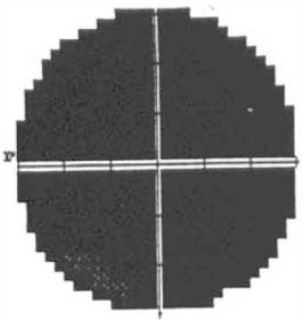

VL $\quad 6 / 36$

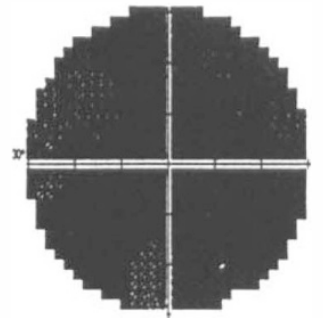

VR $\quad 6 / 6$
Fig. 2. Humphrev 30-2 fields of the patient with the 11778 mutation who recovered vision.

or without other secondary mutations) was $26.1 \pm 11.1$ years (mean \pm standard deviation) for 94 males and $27.7 \pm 11.2$ years for 17 females. The median age for visual loss, however, was 24 years.

\section{Mutation 3460}

Families with mutation 3460 originated from near London. Seven affected individuals from 2 families had the 3460 mutation. ${ }^{27}$ Two patients reported visual recovery from less than $6 / 60$ in both eyes; 1 female could see VR 6/12 VL 6/12, with patchy field loss (Fig. 3), while the other, a male, was slightly mentally retarded and could read VR 6/18 VL 6/18. The remaining 5 had dense centrocecal scotomata and acuities less than 6/60. Colour vision loss was non-specific. Two patients had sensorineural hearing loss and 2 had epilepsy.

The mean age of onset was $28.0 \pm 7.0$ years (the median age was also 28 years) for 5 males and $19.5 \pm 2.5$ years for 2 females.

\section{Mutation 14484}

Families with mutation 14484 originated from south of London, and are genealogically a very old family with descendants in Australia, the United Kingdom and probably the United States. Both families with the 14484 and 13708 mutations ${ }^{19}$ had a large number of individuals recovering vision. Of 20 patients examined $50 \%$ had recovered from less than $6 / 60$ in both eyes to visual acuities better than $6 / 24$. Recovery was likely if the visual loss occurred before the median age of visual loss of 27 years. ${ }^{19}$ The visual field usually showed a centrocecal scotoma; how-

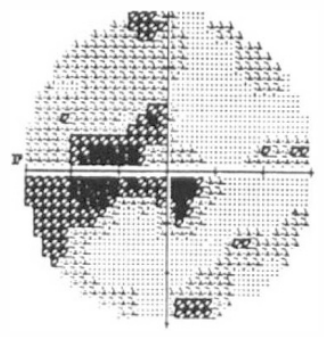

VL $\quad 6 / 6$

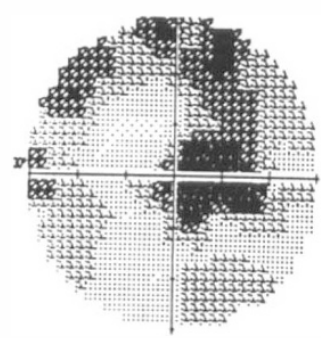

VR

$6 / 5$
Fig. 4. Humphrey 30-2 fields of a patient with the 14484 mutation who recovered vision almost completely.

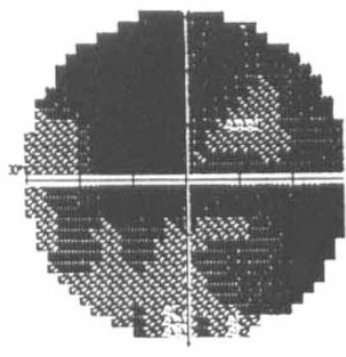

VL $\quad 6 / 12$

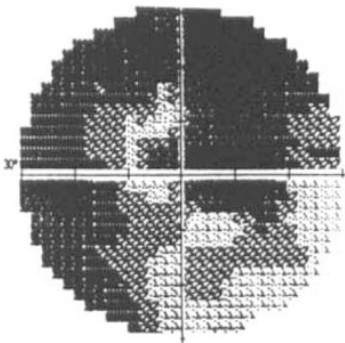

VR $\quad 6 / 12$
Fig. 3. Humphrey 30-2 fields of the patient with the 3460 mutation who recovered vision.

ever, in patients who recovered, the scotoma seemed to constrict rather than to fenestrate, leaving an enlarged blind spot. Recovery usually occurred over 6 months as the acuity improved (Fig. 4). The best improvement documented was to VR 6/4 VL 6/4, with slight residual enlargement of the blind spot. The visual recovery was documented at 2 monthly intervals over the acute phase of the disease in the younger brother of 2 affected patients (Fig. 5). Most patients could do the Farnsworth-Munsell 100 Hue test and scored better than the 11778 patients, with an error more often in the tritan axis.

The mean age of visual loss for 23 males was $29.0 \pm 12.6$ years and for 8 females, $27.4 \pm 16.6$ years.

\section{Mutation 4160}

The apparently unique family with mutation 4160 originated from south of Glasgow. The Qld family with the 4160 and 14484 mutations was described well by David

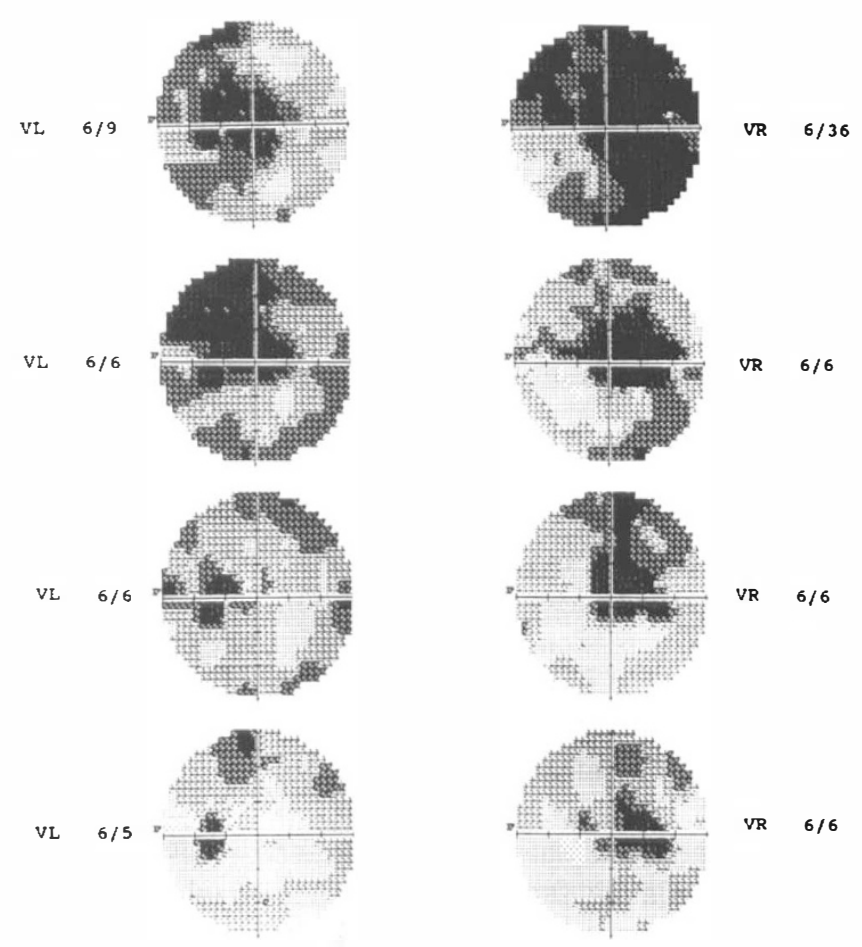

Fig. 5. Humphrey 30-2 fields of a young patient with the 14484 mutation who recovered vision and had fields done every 2 months. The field tests show both decline and recovery. 


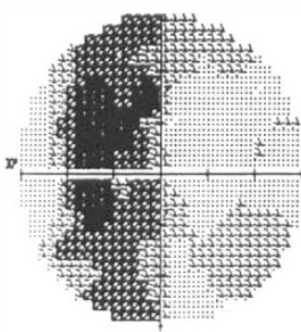

VL $\quad 6 / 24$

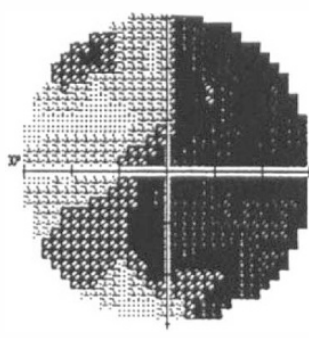

VR $2 / 60$
Fig. 6. Humphrey 30-2 fields of a patient with the 4160 and 14484 mutations who partially recovered vision.

Wallace. ${ }^{6}$ Since his report no further episodes of juvenile encephalopathy have occurred, with the possible exception of one 23-year-old man who had a meningitis-like illness. Twelve of the 23 living affected individuals and 3 unaffected females and one as yet unaffected boy were examined. The age at onset of visual loss and neurological symptoms is sometimes difficult to state as many start in the first decade of life. Equally it is difficult to obtain reliable visual acuities at the worst stage of the disease in those who lost vision in the first decade, but most who lose vision as teenagers report that their acuities were less than $6 / 60$. Every male over 10 years had some degree of visual loss ranging from VR 6/12 VL 6/18 and quite variable visual field loss (Fig. 6) to VR PL VL PL. Again there seemed to be better acuities in those who lost vision at a younger age. Neurological symptoms and signs could occur before or after the eye problems. Usually the first symptoms are of paresthaesiae in the hands and feet; later, variable sensory loss and spastic paraplegia may develop as well as dysarthria. One man lost vision at age 22 years and a year later had a meningitis-like illness. Now 10 years later he has severe visual loss (VR PL, VL PL), with paresthaesiae in the hands and feet, but no objective neurological findings. Three women aged 40 years, 25 years and 17 years were quite normal, as was one 10-yearold boy. There was no documentation nor any photograph of classic LHON discs available. Colour vision loss was variable with the acuity and more often in the protan axis.

\section{Mutation 15257?}

One singleton Italian patient had the 15257 mutation and had lost vision to less than $6 / 60$ in both eyes, then recovered vision to $6 / 18$ in both eyes. ${ }^{28}$ She had no other neurological abnormalities. The Qld2 family had this mutation in association with the $11778 \mathrm{G}$ to A mutation but seemed classic for the clinical description of the 11778 mutation.

All multi-generational families in Australia have an identified mutation. No family had the $15257 \mathrm{G}$ to A mutation without the primary $11778 \mathrm{G}$ to A mutation. In fact there is no published pedigree of LHON in the world literature with the 15257 mutation alone. No family had LHON associated with dystonia as described in the literature. ${ }^{2.8}$

\section{DISCUSSION}

\section{Age of Visual Loss}

In the largest study on age of visual loss by Bell' the age of visual loss for 669 males was $23.2 \pm 10.0$ years and for 113 females it was $25.2 \pm 13.3$ years. In the study by Newman et al..$^{20}$ on patients with the 11778 mutation, the age of onset of visual loss was $26.2 \pm 13.0$ years for 59 males and $34.0 \pm 13.3$ years for 13 females. This study has similar findings, loss of vision occurring at a mean age of 26.1 years for males and 27.7 years for females. All studies show a slight skew with a younger median age. Johns et al..$^{22}$ found a mean age of onset for men and women with the 3460 mutation of 29 years. Johns et al..$^{23}$ found a mean age of onset for men and women with the 14484 mutation of 27 years. This study gives similar results and importantly both of our groups show that the younger the age of onset the more likely the recovery of vision. This has important clinical and research significance. When counselling a patient from a 14484 family who is young (less than 20 years) an optimistic prediction for some recovery of vision is possible. The potential for finding factors which may promote visual recovery in LHON is possible. Studies into the subpopulation of ganglion cells which recover are likely to give some clues as to the pathophysiological mechanism of the disorder. It was not possible to give the mean age of onset in the 4160 mutation accurately as this was often in the first decade, and children of this age are not reliable historians. The oldest male patient, to lose vision with the 4160 and 14484 mutations, however, was 22 years old.

Onset of visual loss between the two eyes is virtually impossible to assess accurately as patients often miss the early subtle changes in the first eye.

\section{Final Visual Acuity and Fields}

The 11778 mutation is associated with a large centrocecal scotoma and rare recovery of vision. If recovery occurs it seems to be due to fenestration of the central scotoma. ${ }^{20.21}$ The rate of recovery, around $2 \%$ in this study, corresponds with that in other studies. ${ }^{20}$ The 3460 mutation was associated with a greater rate of visual recovery ( 2 of 7$)$, which is similar to the findings of Johns et al. ${ }^{22}$ of $20 \%$. The 14484 families are definitely associated with a better visual prognosis ${ }^{19.23}$ and the patients in Johns et al.'s study probably include members of the family from Montreal ${ }^{29.30}$ who showed consistent recovery in $50 \%$ of cases. The acuity and fields of the Qld 1 family with both the 4160 and 14484 mutations is similar to that of the other 14484 families, with recovery seeming to occur in younger-onset patients.

\section{Colour Vision}

It is not possible to compare accurately the colour vision in this study, but the results may suggest that a different population of ganglion cells recover in the 14484 mutation, where the error is mainly in the tritan axis. This may give some possible clues to the pathophysiology of LHON. 


\section{Neurological Abnormalities}

Although LHON in women may be incorrectly diagnosed as multiple sclerosis (MS), ${ }^{31}$ an MS-like syndrome has been described in several studies. ${ }^{3.5 .9 .10 .32 .33}$ So far only one patient with an MS-like syndrome carrying the 11778 mutation has been found in Australia.

Hearing loss was reported in some family members with the 3460 mutation. Pedigrees of mitochondrially inherited hearing loss are known, ${ }^{34}$ as are mitochondrial pedigrees of antibiotic-induced deafness. ${ }^{35.36}$ Brainstem auditory evoked potentials have been found to be abnormal in some cases of LHON, ${ }^{37}$ although these patients did not have hearing loss.

Association with Charcot-Marie-Tooth (CMT) disease has also been reported ${ }^{38.39}$ However, the Australian family NSW $1^{38}$ with CMT and LHON has the 11778 mutation and the two diseases seem to be independently inherited.

Dystonia and LHON have been reported in a few families in the United States, The Netherlands and England. ${ }^{2.8 .40 .41}$

The Qld1 family with juvenile encephalopathy, ${ }^{6.18 .42-4+}$ and probably with $100 \%$ penetrance, is unique. Qld1 may possibly be related to the family described by Wilson. ${ }^{+}$ The disease is becoming less severe in that no recent cases of death from juvenile encephalopathy have been described since the family was originally reported in 1970. Most of those affected with dysarthria, peripheral sensory loss and spasticity were affected at a young age and are now over 40 years old. Originally they were thought to have polio, although the symptoms were not really clinically similar.

\section{ECG Findings}

Preliminary electrocardiographic findings for families Tas1 (11778), Tas2 (14484) and Tas3 (3460) were given by Bower et al..$^{45}$ and abnormalities do not appear to be any more frequent than in the general population. ${ }^{20}$ However, there were several cases of unexplained sudden death in early adult life, including the Tas 3 patient reported. ${ }^{45}$

\section{CONCLUSION}

It is apparent from this study and those in the United States that mitochondrial genotypes are associated with variations in the phenotypes of LHON.

1. The $11778 \mathrm{G}$ to $\mathrm{A}$ and $3460 \mathrm{G}$ to A mutations are associated with classic visual loss, rare recovery of vision (fenestration of the scotoma was seen if recovery occurred) and occasional neurological abnormalities (including an MS-like syndrome).

2. The $14484 \mathrm{~T}$ to $\mathrm{C}$ mutation is associated with frequent recovery of vision and constriction of the scotomata, especially if visual loss occurs at a younger age.

3. The $4160 \mathrm{~T}$ to $\mathrm{C}$ with the $14484 \mathrm{~T}$ to $\mathrm{C}$ mutation family (Qld1) appears unique in the literature and is associated with almost $100 \%$ penetrance of the disorder. The visual loss is again quite variable, with patients losing vision at a younger age having a better final acuity and field. Neurological abnormalities include the now rare juvenile encephalopathy and peripheral paresthaesiae with variable degrees of sensory loss, spasticity and dysarthria.

All three of these phenotypes have come from the United Kingdom. Thus genetic testing of at least one family member may confirm the diagnosis and allow a better understanding of the clinical prognosis for patients affected with LHON. Simpler methods of doing this DNA testing have recently been described. ${ }^{23.24}$

I would very much like to thank Neil Howell and his laboratory at UTMB Galveston, Texas, for the considerable work they have done in sequencing the mitochondrial DNA from both Australian and United Kingdom families with LHON. I would also like to thank Nancy Newman and Don Johns for their advice with this manuscript.

Key words: Deafness, Leber hereditary optic neuropathy, Mitochondrial DNA. Multiple sclerosis, Optic nerve, Optic nerve atrophy, Visual acuity, Visual fields.

\section{REFERENCES}

1. Bell J. Hereditary optic atrophy (Leber's disease). In: Pearson $\mathrm{K}$, editor. The treasury of human inheritance. Cambridge: Cambridge University Press, 1931:325-423.

2. Novotny EJ Jr, Singh G, Wallace DC, et al. Leber's disease and dystonia: a mitochondrial disease. Neurology 1986;36: 1053-60.

3. Palan A. Stehouwer A, Went LN. Studies on Leber's optic neuropathy: III. Doc Ophthalmol 1989;71:77-87.

4. Wilson J. Leber's hereditary optic atrophy: some clinical and aetiological considerations. Brain 1963;86:347-62.

5. Lees F, Macdonald A-ME, Turner JWA. Lcber's disease with symptoms resembling disseminated sclerosis. J Neurol Neurosurg Psychiatry 1964;27:415-21.

6. Wallace C. A new manifestation of Leber's disease and a new explanation for the agency responsible for its unusual pattern of inheritance. Brain 1970;93:121-32.

7. Went LN. A sex-linked heredo-degenerative neurological disorder associated with Leber's optic atrophy: genetical aspects. Acta Genet 1964:14:220-39.

8. Bruyn GW, Went LN. A sex-linked heredo-degenerative neurological disorder, associated with Leber's optic atrophy. I. Clinical studies. J Neurol Sci 1964;1:59-80.

9. De Weerdt CJ, Went LN. Neurological studies in families with Leber's optic atrophy. Acta Neurol Scand 1971; 47:541-54.

10. Harding AE, Sweeney MG, Miller DH et al. Occurrence of a multiple sclerosis-like illness in women who have a Leber's hereditary optic neuropathy mitochondrial DNA mutation. Brain 1992;115:979-89.

11. Leber T. Ueber hereditare und congenital-angelegte Sehnervenleiden. Graefes Arch Ophthalmol 1871;2:249-91.

12. Arts WFM, Scholte HR, Boggard JM, et al. NADH-CoQ reductase deficient myopathy: successful treatment with riboflavin. Lancet 1983:2:581-3.

13. Lessell S, Gise RL, Krohel GB. Bilateral optic neuropathy with remission in young men: variation on a theme by Leber? Arch Neurol 1983;40:2-6.

14. Nikoskelainen EK, Hoyt WF, Nummelin KU. Ophthalmoscopic findings in Leber's hereditary optic neuropathy. II. The fundus findings in the affected family members. Arch Ophthalmol 1983;101:1059-68.

15. Mackey DA. Buttery RG. Leber hereditary optic neuropathy in Australia. Aust NZ J Ophthalmol 1992;20:177-84.

16. Mackey DA. The epidemiology of Leber hereditary optic neuropathy in Australia. Clin Neurosci 1994 (in press). 
17. Hamilton JB. The significance of heredity in ophthalmology: preliminary survey of hereditary eye diseases in Tasmania. Br J Ophthalmol 1938;22:129-32.

18. Howell N. Kubacka I, Xu M, McCullough DA. Leber hereditary optic neuropathy: involvement of the mitochondrial ND1 gene and evidence for an intragenic suppressor mutation. Am J Hum Genet 1991;48:935-42.

19. Mackey DA, Howell N. A variant form of Leber hereditary optic neuropathy characterised by recovery of vision and a multistep mitochondrial genetic etiology. Am J Hum Genet 1992;51:1218-28.

20. Newman NJ, Lott MT, Wallace DC. The clinical characteristics of pedigrees of Leber's hereditary optic neuropathy with the 11778 mutation. Am J Ophthalmol 1991;111: 750-62.

21. Stone EM, Newman NJ, Miller NR, Johns DR, Lott MT, Wallace DC. Visual recovery in patients with Leber's hereditary optic neuropathy and the 11778 mutation. J Clin Neuro-Ophthalmol 1992;12:10-4.

22. Johns DR, Smith KH, Miller NR. Leber's hereditary optic neuropathy: clinical manifestations of the 3460 mutation. Arch Ophthalmol 1992;110:1577-81.

23. Johns DR, Heher KL, Miller NR, Smith KH. Leber's hereditary optic neuropathy: clinical manifestations of the 14484 mutation. Arch Ophthalmol 1993;111:495-8.

24. Mackey DA, Nasioulas S, Forrest S. Finger prick blood testing in Leber hereditary optic neuropathy. Br J Ophthalmol 1993;77:311-2.

25. Optic Neuritis Study Group. The clinical experience of the optic neuritis treatment trial. Arch Ophthalmol 1991; 109:1673-8.

26. Smith JL, Hoyt WF, Susac JO. Ocular fundus in acute Leber optic neuropathy. Arch Ophthalmol 1973;90:349-54.

27. Howell N, Bindoff LA, McCullough DA, et al. Leber hereditary optic neuropathy: identification of the same mitochondrial ND1 mutation in six pedigrees. Am J Hum Genet 1991;49:939-50.

28. Howell N, Kubacka I, Halvorson S, Mackey DA. Leber's hereditary optic neuropathy: the aetiological role of a mutation in the mitochondrial cytochrome $b$ gene. Genetics 1993; 133:133-6.

29. Brunette JR, Bernier RG. Diagnosis et prognostic de la maladie de Leber: incidence de la récuperation totale spontanée. Union Med Can 1970;99:643-52.

30. Bird A, McEachern D. Leber's hereditary optic atrophy in a Canadian family. Can Med Assoc J 1949;61:376-83.
31. Franks WA, Sanders MD. Leber's hereditary optic neuropathy in women. Eye 1990;4:482-5.

32. Taylor J, Holmes GM. Nervous symptoms associated with optic atrophy of the familial type. Trans Ophthalmol Soc UK 1913;33:116-38.

33. Went LN, Bruyn GW. The genetics of Leber's optic atrophy and its neurological sequelae. J Genet Hum 1966;15:332-7.

34. Jaber L, Shohat M, Bu X, et al. Sensori-neural deafness inherited as a tissue specific mitochondrial disorder. J Med Genet 1992;29:86-90.

35. Hu DN, Qiu Wei-Qin, Wu Bao-Ton, et al. Genetic aspects of antibiotic induced deafness: mitochondrial inheritance. J Med Genet 1991;28:79-83.

36. Prezant TR, Agapian JV, Bohlman MC, et al. Mitochondrial ribosomal RNA mutation associated with both antibioticinduced and non-syndromic deafness. Nature Genet 1993:4:289-93.

37. Mondelli M, Rossi A, Scarpini C. Dotti MT, Federico A Leber's optic atrophy: VEP and BAEP changes in 16 asymptomatic subjects. Acta Neurol Scand 1991;84:366.

38. McLeod JG, Low PA. Morgan Hughes JA. Charcot-MarieTooth disease with Leber optic atrophy. Neurology 1978;28:179-84.

39. McCluskey DJ, O’Connor PS, Sheehy JT. Leber's optic neuropathy and Charcot-Marie-Tooth disease: report of a case. J Clin Neuro-Ophthalmol 1986;6:76-81 .

40. Bruyn GW, Vielvoye GJ, Went LN. Hereditary spastic dystonia: a new mitochondrial encephalopathy. Putaminal necrosis as a diagnostic sign. J Neurol Sci 1991;103:195-202.

41. Marsden CD, Lang AE, Quinn NP, McDonald WI, Abdallat A, Nimri S. Familial dystonia and visual failure with striatal CT lucencies. J Neurol Neurosurg Psychiatry 1986;49: 500-9.

42. Wallace DC. Leber's optic atrophy: a possible example of vertical transmission of a slow virus in man. Aust Ann Med 1970;3:259-62.

43. Parker WD Jr, Oley CA, Parks JK. A defect in mitochondrial electron-transport activity (NAHD-coenzyme Q oxidoreductase) in Leber's hereditary optic neuropathy. $\mathrm{N}$ Engl $\mathrm{J}$ Med 1989:320: 1331-3.

44. Howell N, McCullough DA. An example of Leber hereditary optic neuropathy not involving a mutation in the mitochondrial ND4 gene. Am J Hum Genet 1990;47:629-34.

45. Bower SPC, Hawley I, Mackey DA. Cardiac arrhythmia and Leber's hereditary optic neuropathy. Lancet 1992;339: 1427-8. 